\title{
Assessing the Benefits of Hybrid Cycloconverters
}

\author{
Tianning XU, Christian KLUMPNER, Jon CLARE \\ Department of Electrical and Electronic Engineering, Faculty of Engineering \\ UNIVERSITY OF NOTTINGHAM, UK
}

klumpner@ieee.org

\begin{abstract}
Power converters consisting of naturally commutated thyristors such as cycloconverters and current source inverters were the first used in driving electrical motors with variable speed but now due to their inferior performance compared to forced commutated converters, their use is restricted in the high voltage/high power range where the performance and cost of forced commutated switching devices is not competitive yet. Hybrid cycloconverters proposed recently are capable of improving the performance of cycloconverters by adding an auxiliary forced commutated inverter with reduced installed power. It will be shown that the new topology is not only able to improve the quality of the output voltage, but also to enhance the control over the circulating current and therefore, for some of the cycloconverter arrangements, to improve the input power quality. This paper evaluates the performance of a few standard and hybrid cycloconverter arrangements using both simulation and experimental results.
\end{abstract}

\section{INTRODUCTION}

A cycloconverter [1]-[10] comprises of a network of naturally commutated thyristors that bidirectionally connect each of the input lines to each of the output lines as shown in Fig. 1. There are many topologies in use depending on the number of pulses of the thyristor bridges (6-12-18-24 etc) and if their operating mode is circulating current mode (CCM) or circulating current-free mode (CCFM). The output voltage is controlled by modulating the firing angle to generate an $\mathrm{AC}$ output voltage of adjustable frequency and amplitude. Even though the operation is straightforward, there are some disadvantages: i) the frequency of the load side voltage can only be a fraction, typically $1 / 3$, of the supply frequency depending on the number of the pulses due to the high content of harmonics present in the output voltage; ii) the poor input power factor due to the high content of harmonics, inter-harmonics and even sub-harmonics present in the input current; iii) poor control over the circulating current when the cycloconverter operates in circulating current mode causes a large amount of reactive power drawn from the supply and further degrades the power quality on the input side.

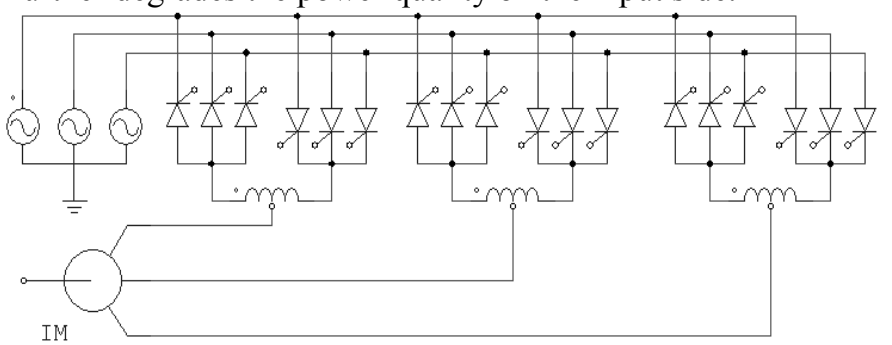

Fig. 1. Topology of a standard 3-pulse (or 6-pulse in CCM) cycloconverter.
A good synthesis of both the output voltage and the input current waveform can be achieved by increasing the number of pulses. This is realized by employing a multiphase (more than 3 phase) supply with a small phase displacement between the supply phase voltages or by using phase-shifting transformers (delta-star or autotransformers) in a standard three-phase supply. The drawback of using a high number of pulses is that the assembly requires a large number of devices and it is rather bulky, as the transformers are designed for full power. Although the circulating current can be much reduced by employing circulating current reactors (CCR), this is also at the expense of increasing the complexity of the whole circuit since the size of inductors is dependent on the frequency of the ripple (number of pulses). However, the cycloconverter is still used in the very high power range (tens-hundreds MW) drives, where there is no other type of semiconductor switch available.

A new topology based on the hybrid approach [11]-[12], the hybrid cycloconverter, has been proposed [13]-[14] to mitigate these problems by connecting an auxiliary inverter with lower voltage rated devices in each of the output phases of the cycloconverter. This paper further validates the feasibility of the hybrid approach by evaluating the standard and the hybrid cycloconverter arrangements (in CCM \& CCFM) through the implementation of both the simulation model as well as the experimental prototype.

\section{THE HYBRID CYCLOCONVERTER}

The key to reduce the size of magnetic components is to increase the frequency of the ripple by employing an auxiliary forced commutated power converter operating in a similar way to a series connected active filter [13]-[14]. The auxiliary converter will reduce/cancel the low frequency ripple present in the output voltage and facilitate accurate control over the circulating current by switching faster whilst being rated at only a fraction of the supply voltage.

\section{A. Hybrid Cycloconverter in Circulating Current Mode}

Cycloconverters operating in circulating current mode are known to offer better output voltage waveform, because of the filtering effect provided by the CCR. Fig. 2a shows the topology of a 3-phase/1-phase hybrid cycloconverter using an asymmetric H-bridge inverter with a split DC-link capacitor. Each leg of the H-bridge inverter handles one direction of the load current and the circulating current. The topology will result in low number of forced commutated devices, but since now the load current, having typically a low frequency, passes through the split DC-link capacitors, will maximize their size. 

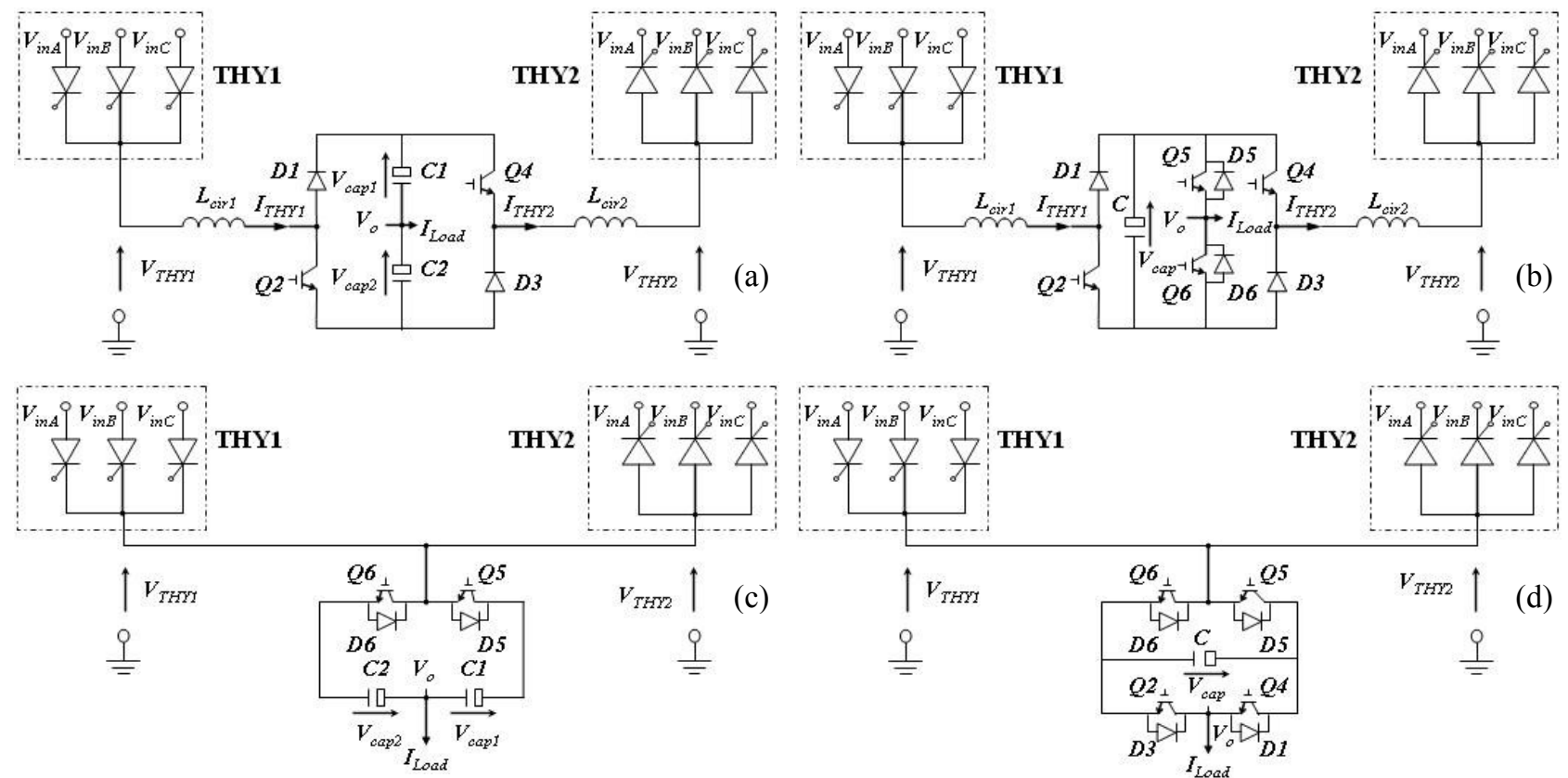

Fig. 2. Topologies of 3-phase/1-phase hybrid cycloconverters operating: a), b) in circulating current mode; c, d) in circulating current-free mode and using a), c) a split DC-link capacitor; or b), d) a single DC-link capacitor

By adding an extra full inverter leg to the auxiliary inverter, as shown in Fig. 2b, the split DC-link capacitors can be merged as only one capacitor, resulting in half of the DC-link capacitor voltage compared to the $\mathrm{H}$-bridge. Moreover, it is also possible to reduce the size of the DC-link capacitor since only a fraction of the load current amplitude at much higher frequency needs to be handled.

\section{B. Hybrid Cycloconverter in Circulating Current-Free Mode}

Cycloconverters operating in circulating current-free mode are known to offer a poorer output voltage waveform quality mainly because at any time, one of the thyristor half bridges (THY1 or THY2) is disabled. However, the lack of a CCR and the circulating current means that the size can be kept small and the input power quality (mainly the reactive power consumed from the power grid) is improved compared to a cycloconverter in circulating current mode with an identical number of pulses. In a similar way, it is possible to derive two hybrid cycloconverter topologies that operate in circulating current-free mode: the topology using a half bridge inverter with split DC-link capacitors as shown in Fig. 2c, since a full inverter leg is able to handle both the positive and negative load current; the topology using a full bridge inverter with a single DC-link capacitor as shown in Fig. 2d. By comparing Fig. 2a, $2 \mathrm{~b}$ with Fig. 2c, 2d, it is clear that the circulating current-free mode hybrid cycloconverter will have a simpler topology but only evaluating the load side and supply side performance will clarify which of the hybrid cycloconverters is actually better.

\section{Control of the Hybrid Cycloconverters}

The control structure to fit both types of hybrid cycloconverters is presented in Fig. 3. The control circuit mainly comprises four parts:

\section{i) Differential Mode Voltage Control}

The differential mode voltage control, as shown in the blue-background block in Fig. 3, is only needed if the hybrid cycloconverter operates in circulating current mode. By injecting a counter component of the differential mode voltage between the two halves of the thyristor bridge with the auxiliary inverter, the low frequency harmonics contained in the differential mode voltage can be cancelled, resulting in only high frequency ripple added on the circulating current. A fast PI controller is used in order to accurately control the circulating current, which in this approach is measured but an important issue in future research will be the removal of this current transducer. In order to produce the actual differential mode voltage reference $\left(V_{D M}\right)$ that needs to be synthesized by the auxiliary inverter, the output of this controller $\left(V_{c i r}\right)$ which estimates the amount of voltage drop that will appear across the two inductances $\left(L_{\text {cirl }} / L_{\text {cir }}\right)$ in order to make the circulating current $\left(I_{\text {cir }}\right)$ follow its reference $\left(I_{\text {cir }}\right.$ ref $)$ is added to the differential mode voltage $\left(V_{\text {diff }}\right)$ produced by the two thyristor half bridges which is measured or can be estimated based on supply voltage measurements and instantaneous switching state of the thyristors.

\section{ii) Common Mode Voltage Control}

The common mode voltage component produced by the two thyristor half bridges $\left(V_{T H Y 1} \& V_{T H Y 2}\right)$, which in a normal cycloconverter will be its output voltage $\left(V_{\text {out }}\right)$, contains both the desired output frequency component as well as the low order harmonics caused by the way the thyristor devices are commutated. In order to minimize these harmonics, as shown in red-background block in Fig. 3, the output voltage of the standard cycloconverter is subtracted from the reference 


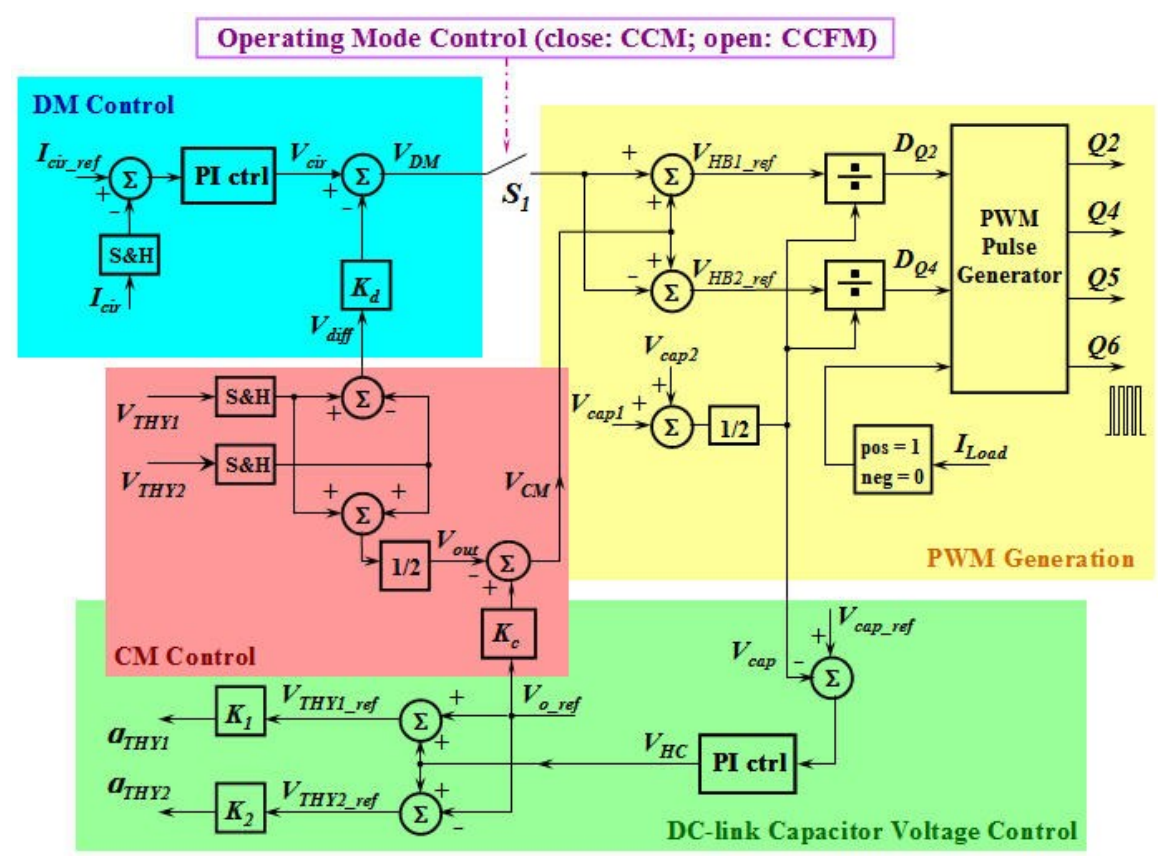

Fig. 3. Principle diagram of the control structure of the hybrid cycloconverter: $K_{l, 2}:$ inverse transfer function of the thyristor bridge $\left(\cos ^{-1}\right) ; K_{d}$ : transfer ratio for the differential mode voltage feedforward compensation; $K_{c}$ : voltage ratio between the fundamental output voltage of the standard cycloconverter and its reference (the whole control diagram is for circulating current mode and the diagram other than the blue-background block is for circulating current-free mode).

ripple-free waveform $\left(V_{o_{-} r e f}\right)$, producing the common-mode voltage $\left(V_{C M}\right)$ that needs to be injected by the auxiliary inverter in order to remove all the unwanted low frequency voltage distortions.

\section{iii) DC-link Capacitor Voltage Control}

In order to ensure proper operation of the auxiliary inverter, as shown in the green-background block in Fig. 3, the average of the capacitor voltages $V_{\text {capl } 1}$ and $V_{\text {cap } 2}$ of the H-bridge (or only $V_{\text {cap }}$ for the three-leg bridge inverter) are monitored by a slow PI controller (as only the average, not the instantaneous capacitor voltage, has to be controlled), which generates a smooth offset signal $\left(V_{H C}\right)$ that is added/subtracted from the reference voltage that produces the firing angles for the two thyristor half bridges THY1 and THY2. When the hybrid cycloconverter operates in circulating current mode, the DC-link capacitor voltage is controlled by controlling the differential mode voltage of the thyristor half bridges as the controlled DC circulating current can charge or discharge the capacitor(s). However, if the cycloconverter operates in circulating current-free mode, the DC capacitor voltage can only be controlled by the common mode voltage as there is no differential mode voltage between the two thyristor half bridges and therefore no circulating current.

\section{iv) PWM Generation}

If the cycloconverter operates in circulating current mode, the differential mode voltage reference $V_{D M}$ and the common mode voltage reference $V_{C M}$ are used to generates the references for the voltage between each leg of the auxiliary inverter and the output of the load side, $V_{\mathrm{HB}_{-} \text {ref }}$ and $V_{\mathrm{HB} 2_{-} \text {ref }}$, as shown in the yellow-background block in Fig. 3. However, if the cycloconverter operates in circulating current-free mode, the $V_{D M}$ will be no use and therefore the differential mode voltage control can be easily isolated by using an operating mode control switch $S_{1}$. The duty-cycles of the $Q 2 \& Q 4$ can be determined by dividing the reference voltage of each inverter leg by the DC-link capacitor voltage. The gate pulses are then produced by the PWM pulse generator block by multiplying the two duty-cycles with the switching period and arranging the switching states of the auxiliary inverter accordingly. The duty cycles of $Q 5 \& Q 6$ can be decided by the states of $Q 2 \& Q 4$ as well as the direction of the load current and the common voltage reference $V_{C M}$ for the auxiliary inverter.

\section{SIMULATION RESULTS}

Simulation models of the standard and hybrid (only Fig. $2 \mathrm{~b}$ and $2 \mathrm{~d}$ ) cycloconverters in both operating modes (CCM \& CCFM) have been implemented in SABER. The circuit parameters used in the simulation models are given in the Appendix A.

\section{A. Standard/Hybrid Cycloconverter in Circulating Current Mode}

Fig. $4 \mathrm{a}$ and $4 \mathrm{~b}$ shows respectively the output voltage generated by the two thyristor half bridges and Fig. $4 \mathrm{c}$ and $4 \mathrm{~d}$ shows their spectra, revealing a 225 $\mathrm{V}_{\mathrm{pk}} @ 5 \mathrm{~Hz}$ common mode component. Due to the difference between the instantaneous output voltages of the two thyristor half bridges, a large differential mode voltage shown in Fig. $4 \mathrm{e}$ is generated. Fig. $4 \mathrm{f}$ shows the spectrum of the differential mode voltage, having the largest harmonic components $\left(187 \mathrm{~V}_{\mathrm{pk}}\right.$ and $\left.161 \mathrm{~V}_{\mathrm{pk}}\right)$ around 150 
Hz. This will cause circulating current that needs to be limited by the CCR.

Fig. 5 compares the load side performance of the standard vs. the hybrid cycloconverter operating in circulating current mode. Fig. 5a and 5c shows that by using the CCR, the output waveform of a standard cycloconverter can obtain a better harmonics performance. However, since the hybrid converter has added functionality, it can further reduce the low order voltage harmonics, such as the largest component from approx. $78 \mathrm{~V}_{\mathrm{pk}}$ (around $150 \mathrm{~Hz}$ ) to $15 \mathrm{~V}_{\mathrm{pk}}$ (Fig. $5 \mathrm{~b}$ and $5 \mathrm{~d}$ ). Another improvement is obtained through the hybrid cycloconverter when analysing the circulating current (Fig. 5e and 5g), which can now be reduced and maintained around a pre-set DC level (Fig. $5 \mathrm{f}$ and $5 \mathrm{~h}$ ). The minimum value of the circulating current is dictated by the thyristor's holding current given in the datasheet and this improvement may provide a more straightforward way of designing the CCR. Due to the highly inductive load, the improvement on the output voltage quality is not very obvious when comparing the waveform of the load current (Fig. $5 \mathrm{i}$ and $5 \mathrm{j}$ ).

\section{B. Standard/Hybrid Cycloconverter in Circulating Current- Free Mode}

Fig. 6 shows by comparison the output performance of the standard vs. the hybrid cycloconverter that operates in circulating current-free mode. Fig. 6a and $6 \mathrm{c}$ reveal that the output voltage waveform looks worse than that of the standard cycloconverter in circulating current mode $\left(104 \mathrm{~V}_{\mathrm{pk}}\right.$ compared to $\left.78 \mathrm{~V}_{\mathrm{pk}} @ 150 \mathrm{~Hz}\right)$. However, the auxiliary inverter is able to improve the spectrum by reducing the harmonics around $150 \mathrm{~Hz}$ to a negligible level, such as $1.47 \mathrm{~V}_{\mathrm{pk}} @ 130 \mathrm{~Hz}$ and $1.43 \mathrm{~V}_{\mathrm{pk}} @ 140 \mathrm{~Hz}$, etc (Fig. 6b and 6d), which is better than the previous case since only the common mode voltage needs to be handled. This improvement is also clearly visible in the shape of the load current (Fig. 6e and 6f).

Fig. 7 shows the PWM voltage and its low-pass filtered component injected by the auxiliary inverter of the hybrid cycloconverter when it operates in circulating current mode (Fig. 7a, only the voltage injected between the midpoint of one asymmetric leg and the output of the symmetric leg is shown) or in circulating current-free mode (Fig. 7b). It can be seen from these two figures that the DC-link capacitor voltage in the auxiliary inverter is around $300 \mathrm{~V}$ since it is equal to the amplitude of the injected PWM voltage.

\section{Input Side Performance}

Fig. 8 shows the waveform and the spectrum of the input currents for all these four situations: operation of the standard vs. the hybrid cycloconverter with and without circulating current. The only noticeable difference is that the standard cycloconverter in circulating current mode (Fig. 8a and 8c) seems to draw a much larger input current at the fundamental frequency than the other three cases, which in conjunction to having the same load, and a very similar input current shape and harmonic profile, reveals that it consumes much more reactive power than the other three cycloconverter arrangements and therefore results in the worst displacement power factor.
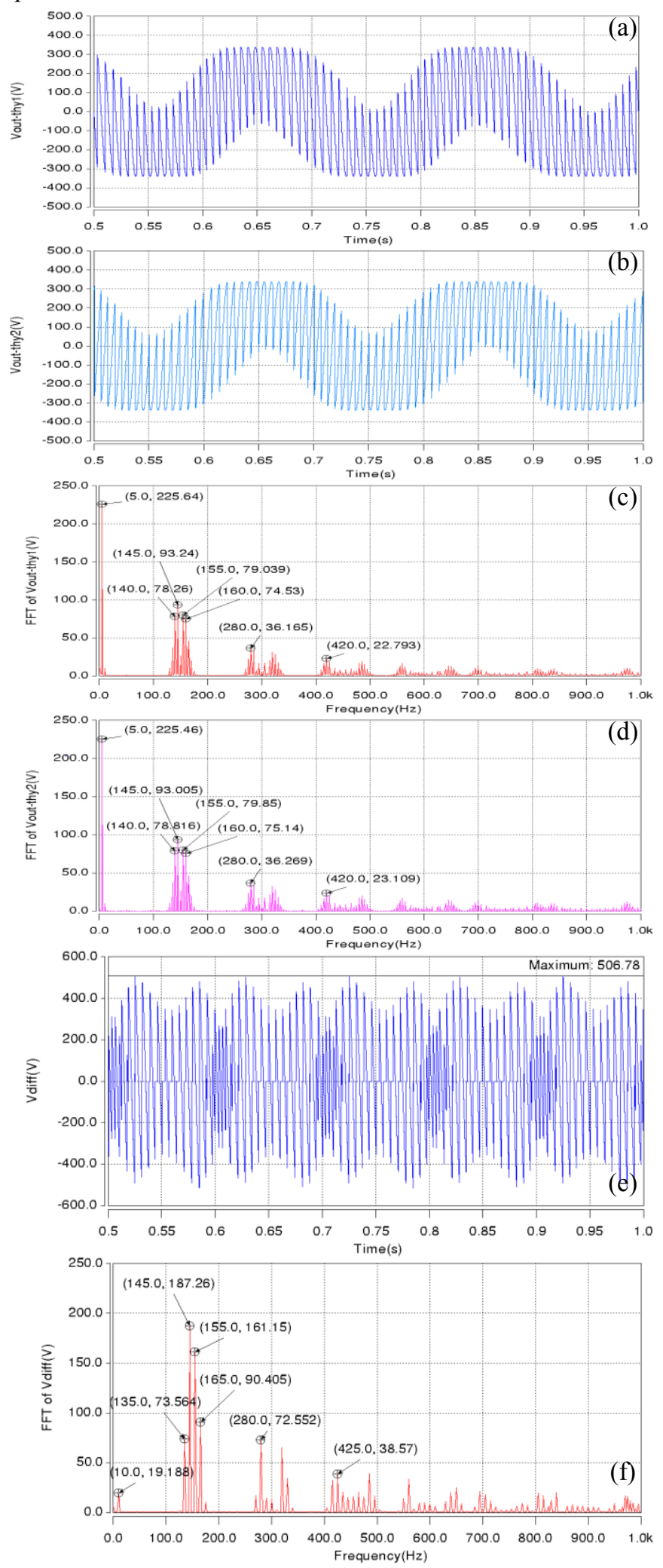

Fig. 4. Simulation results of a standard cycloconverter operating with circulating current: a), b) output voltage on each thyristor half bridge and c), d) the spectrum; e) the differential mode voltage and f) the spectrum. 

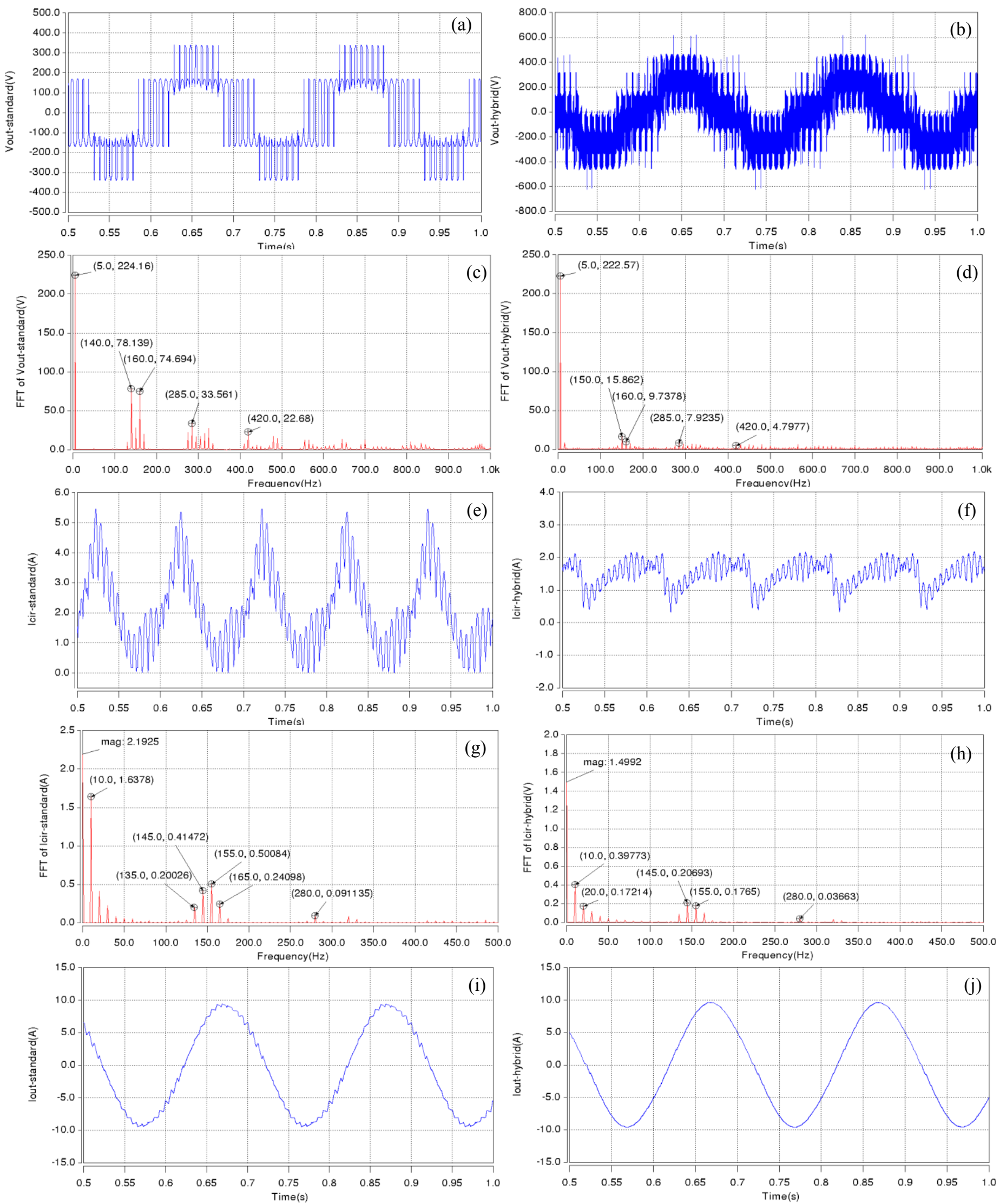

Fig. 5. Simulation results evaluating the performance of the standard vs. the hybrid cycloconverter that operates in circulating current mode: a), b) output voltage and c), d) its spectrum; e), f) circulating current and g), h) its spectrum; i), j) the load current. 

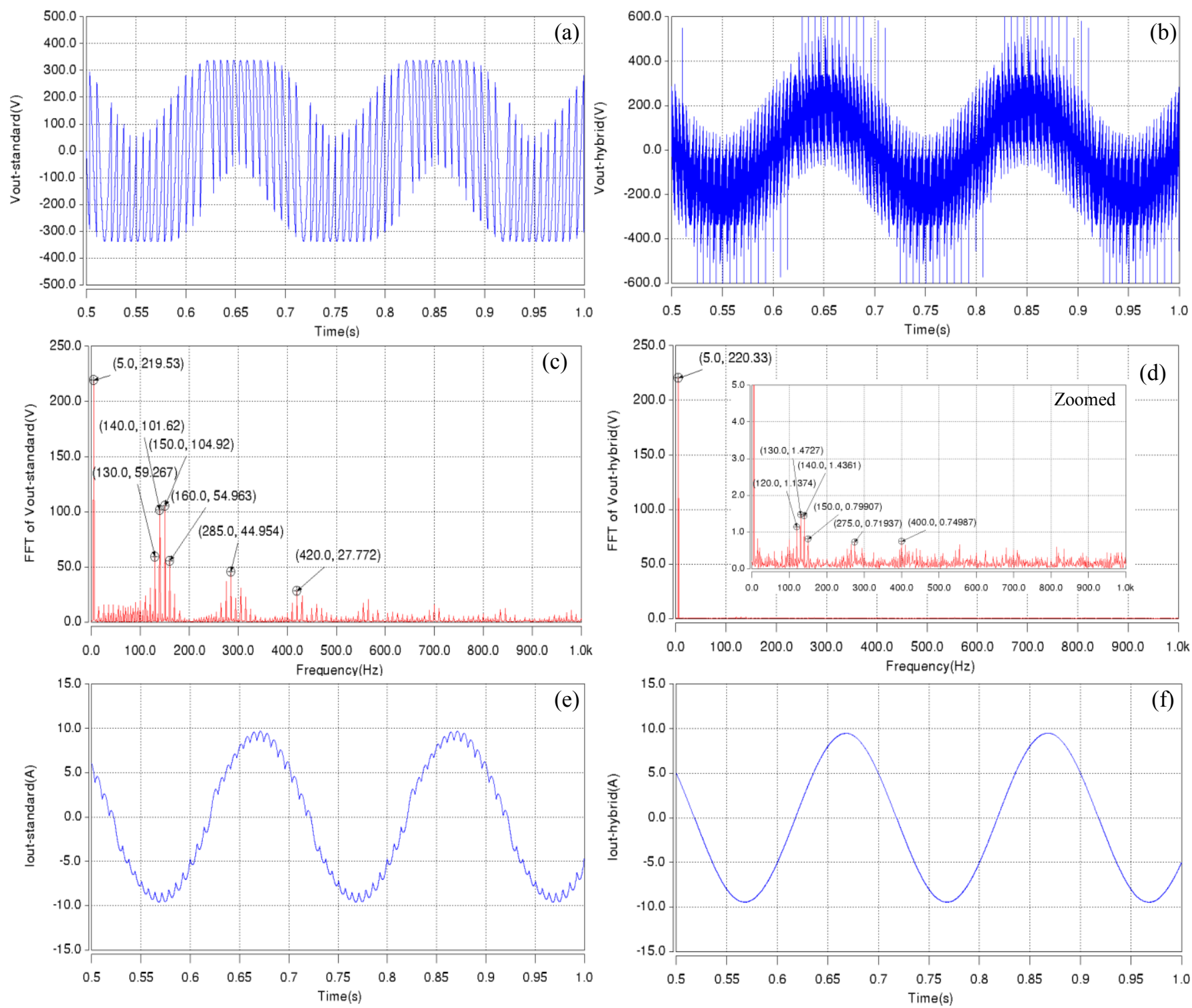

Fig. 6. Simulation results evaluating the performance of the standard vs. hybrid cycloconverter operating in circulating current-free mode: a), b) output voltage and c), d) its spectrum; e), f) the load current.
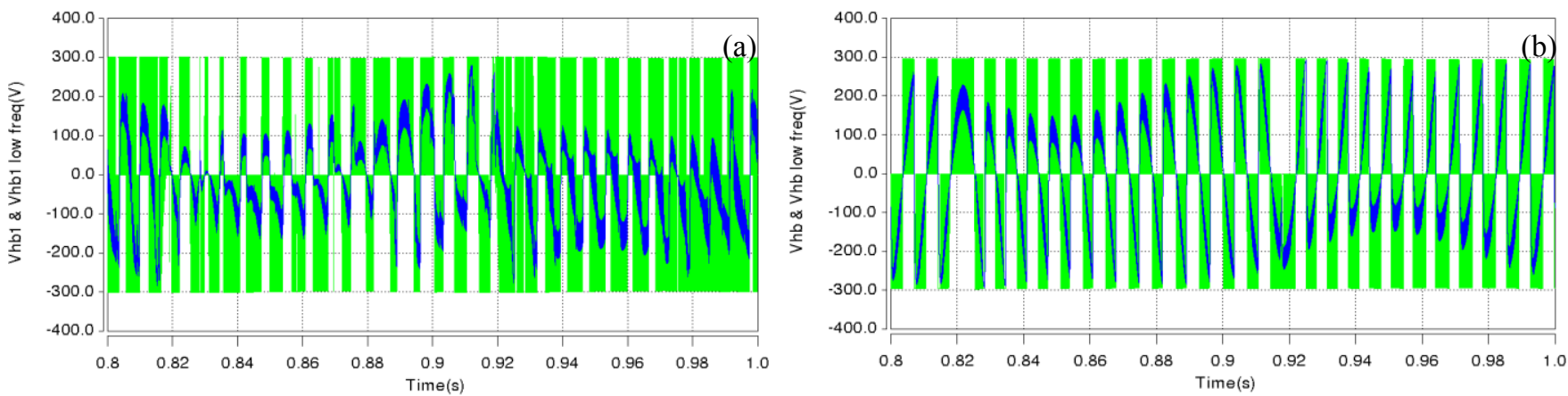

Fig. 7. PWM voltage and its low-pass filtered component injected by the auxiliary inverter of the hybrid cycloconverter operating in: a) circulating mode current (only the voltage between one asymmetric and the full leg is shown) and b) circulating current-free mode. 

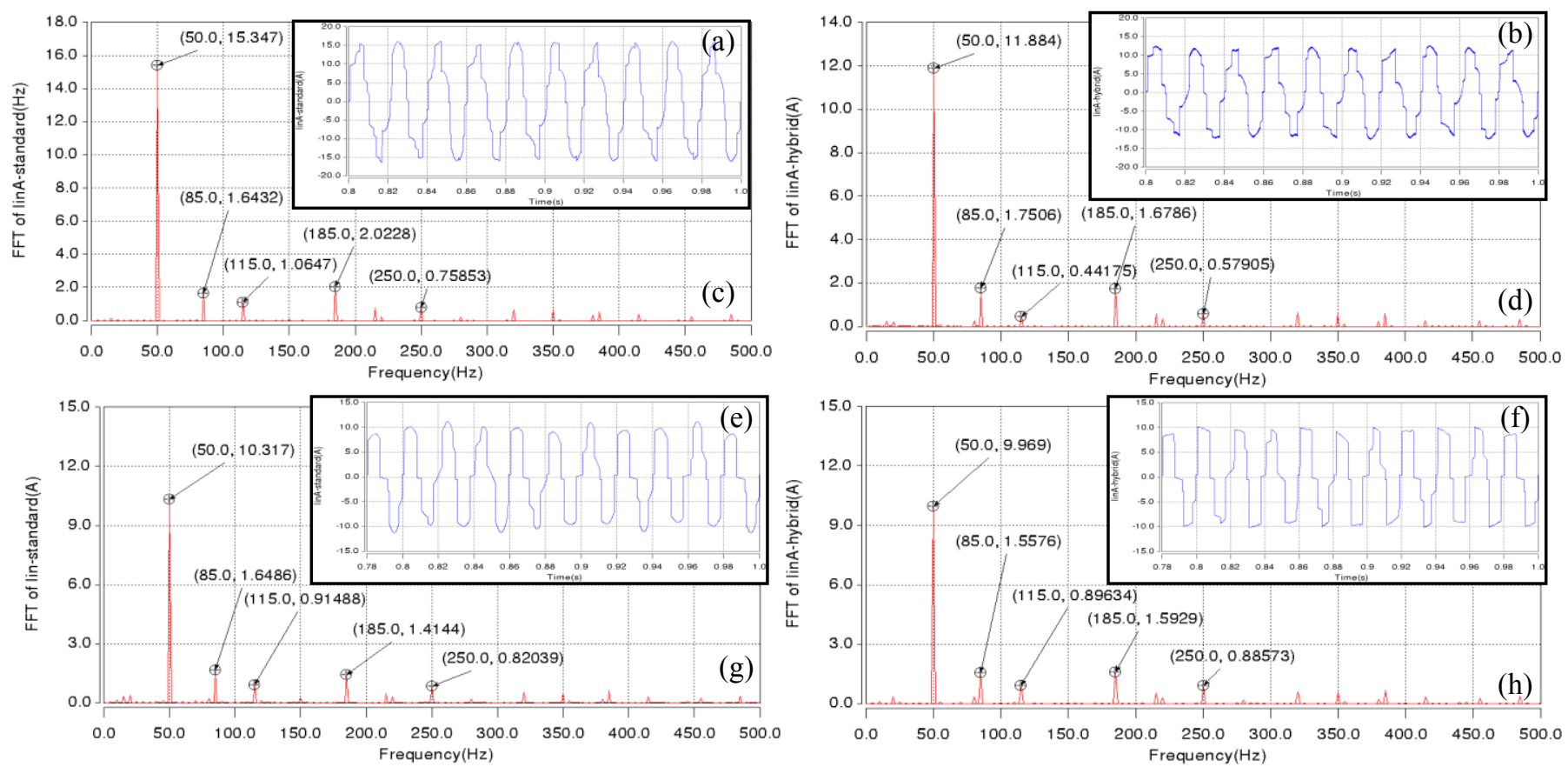

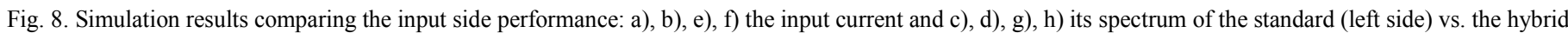
(right side) cycloconverters operating with (upper row)/without (lower row) circulating current.

\section{EXPERIMENTAL RESULTS}

In order to further verify the improvements achieved by the hybrid solution, an experimental prototype was built by using the identical parameters as those in the simulation model (Appendix. A). Fig. 9 shows the operation of the standard vs. hybrid cycloconverter in circulating current mode. The improvements on the output voltage, the circulating current and the load current waveforms are very similar to the simulation results: the voltage harmonics around $150 \mathrm{~Hz}$ present in the standard cycloconverter (Fig. 9a and 9c) has been significantly reduced (less than 1/3) in the hybrid topology (Fig. 9b and 9d) and the presence of a more harmonic-free sinusoidal load current waveform (Fig. 9i and 9j) proves that the control of the hybrid cycloconverter is operating properly; the circulating current (Fig. 9f and 9h) measured in the hybrid cycloconverter by disconnecting the load, is maintained around the 1.5A.set-point with apparently reduced ripples compared to that of the standard cycloconverter (Fig. 9e and 9g).

Fig. 10 shows the experimental results comparing the operation of the standard vs. hybrid cycloconverter in circulating current-free mode. Again, the output voltage waveforms (Fig. 10a and 10c) and their spectra (Fig. 10b and 10d) are very similar to the simulation results, showing an important reduction of the most dominant harmonics around $150 \mathrm{~Hz}$, such as from $108.4 \mathrm{~V}_{\mathrm{pk}}$ to $10.34 \mathrm{~V}_{\mathrm{pk}} @ 140 \mathrm{~Hz}$. This improvement is also verified by the load current waveform of the hybrid cycloconverter (Fig. 10f), where there is no obvious ripple superimposed on the fundamental component compared to that of the standard cycloconverter (Fig. 10e). However, some low order harmonic distortions caused by the errors in firing the incoming thyristors near the zero crossing of the load current are still visible for the hybrid situation.
The operation of the auxiliary inverter in both circulating current and circulating current-free mode are revealed in Fig. $11 \mathrm{a}$ and $11 \mathrm{~b}$ respectively by showing the injected PWM voltage waveform and its low-pass filtered component, which is similar to the simulation results.

Table. 1 below summarizes the WTHD (Weighted Total Harmonic Distortion) of the output voltages generated by different topologies. As it can be seen from this table, the worst situations appear at the thyristor half bridge in circulating current mode and the standard cycloconverter in circulating current-free mode whilst a better performance can be achieved by the standard cycloconverter in circulating current mode. With the added auxiliary inverter, the hybrid cycloconverters in both operating modes are able obtain the best performance at the output side.

Table. 1. WTHD comparison between output voltages in different topologies

\begin{tabular}{|c|c|c|}
\hline Operating Mode & Topology & WTHD (\%) \\
\hline \multirow{3}{*}{ CCM } & Thyristor Half Bridge & 3.64 \\
\cline { 2 - 3 } & Standard Cycloconverter & 2.18 \\
\cline { 2 - 3 } & Hybrid Cycloconverter & 0.82 \\
\hline \multirow{2}{*}{ CCFM } & Standard Cycloconverter & 4.34 \\
\cline { 2 - 3 } & Hybrid Cycloconverter & 0.73 \\
\hline
\end{tabular}

Table. 2. Input side comparison between different topologies

\begin{tabular}{|c|c|c|c|c|}
\hline Operating Mode & Topology & DPF & DF & PF \\
\hline \multirow{2}{*}{ CCM } & Standard & 0.309 & 0.965 & 0.298 \\
\cline { 2 - 5 } & Hybrid & 0.395 & 0.963 & 0.380 \\
\hline \multirow{2}{*}{ CCFM } & Standard & 0.490 & 0.954 & 0.467 \\
\cline { 2 - 5 } & Hybrid & 0.502 & 0.945 & 0.474 \\
\hline
\end{tabular}



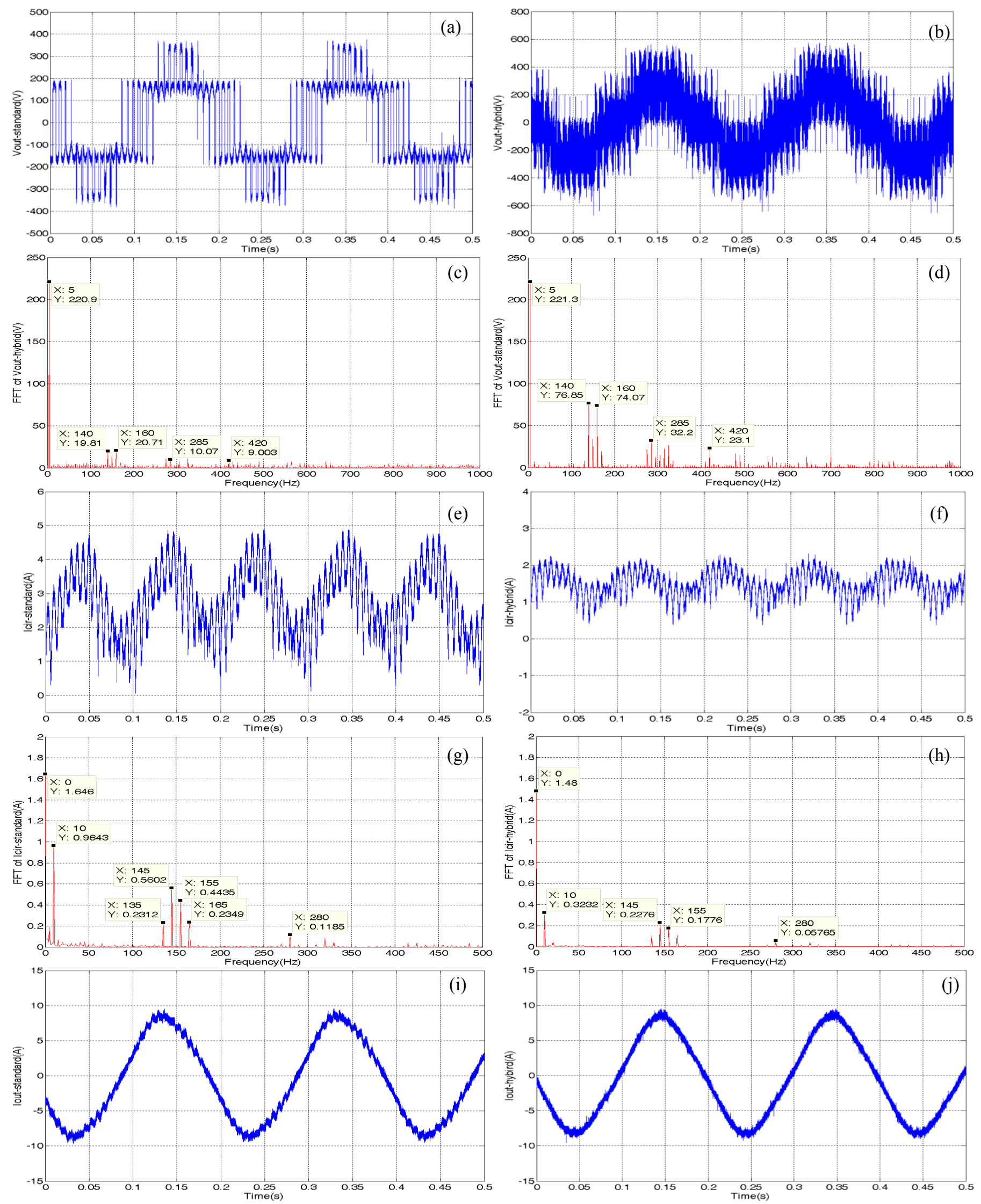

Fig. 9. Experimental results evaluating the performance of the standard vs. the hybrid cycloconverter that operate in circulating current mode: a), b) output voltage and c), d) its spectrum; e), f) circulating current and g), h) its spectrum; i), j) the load current. 

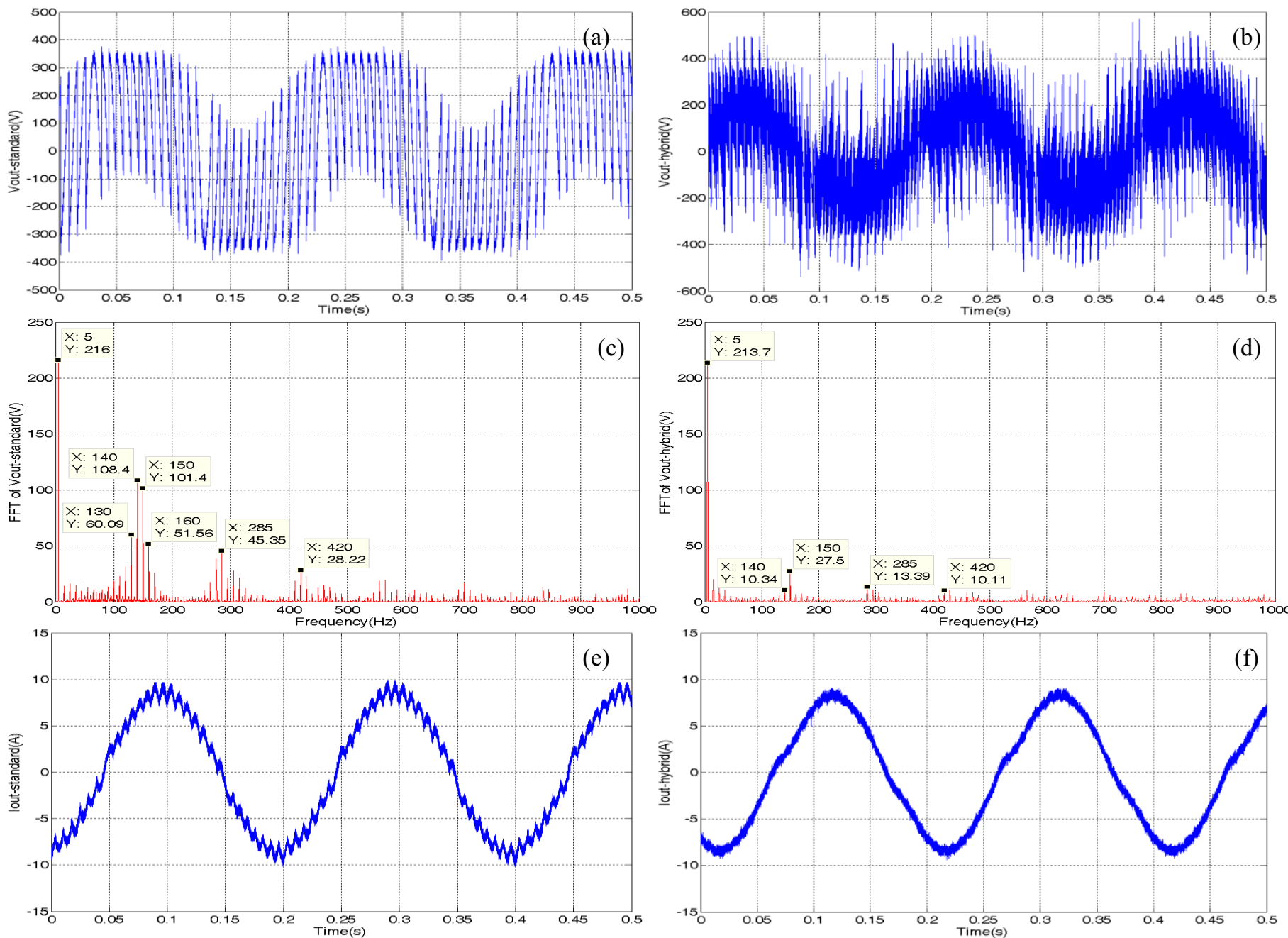

Fig. 10. Experimental results evaluating the performance of the standard vs. hybrid cycloconverter operating in circulating current-free mode: a), b) output voltage and c), d) its spectrum; e), f) the load current.
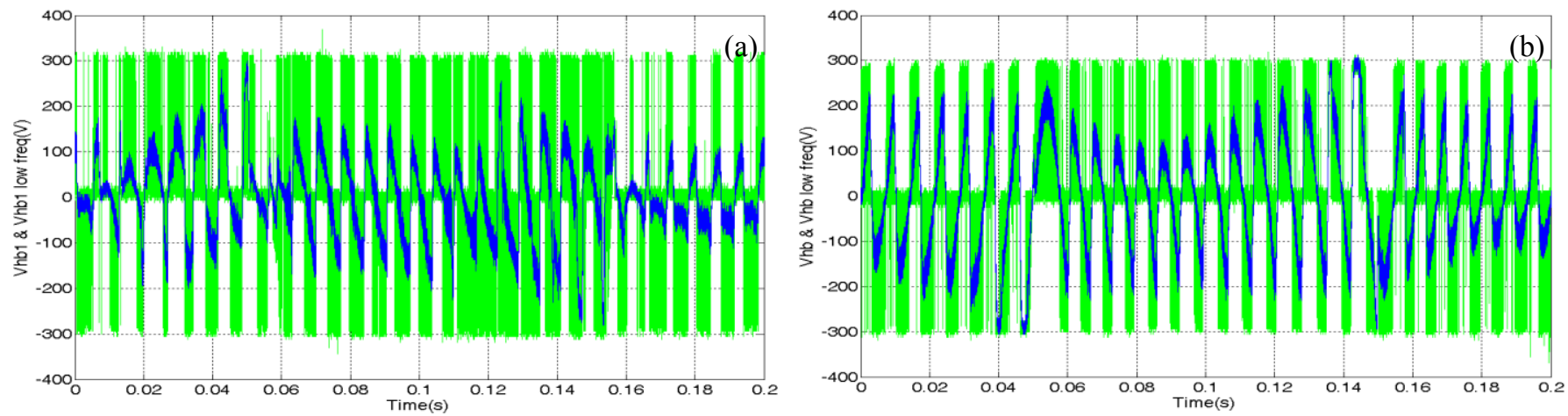

Fig. 11. PWM voltage and its reference injected by the auxiliary inverter of the hybrid cycloconverter operating in: a) circulating mode current (only the voltage between one asymmetric and the full leg is shown) and b) circulating current-free mode. 

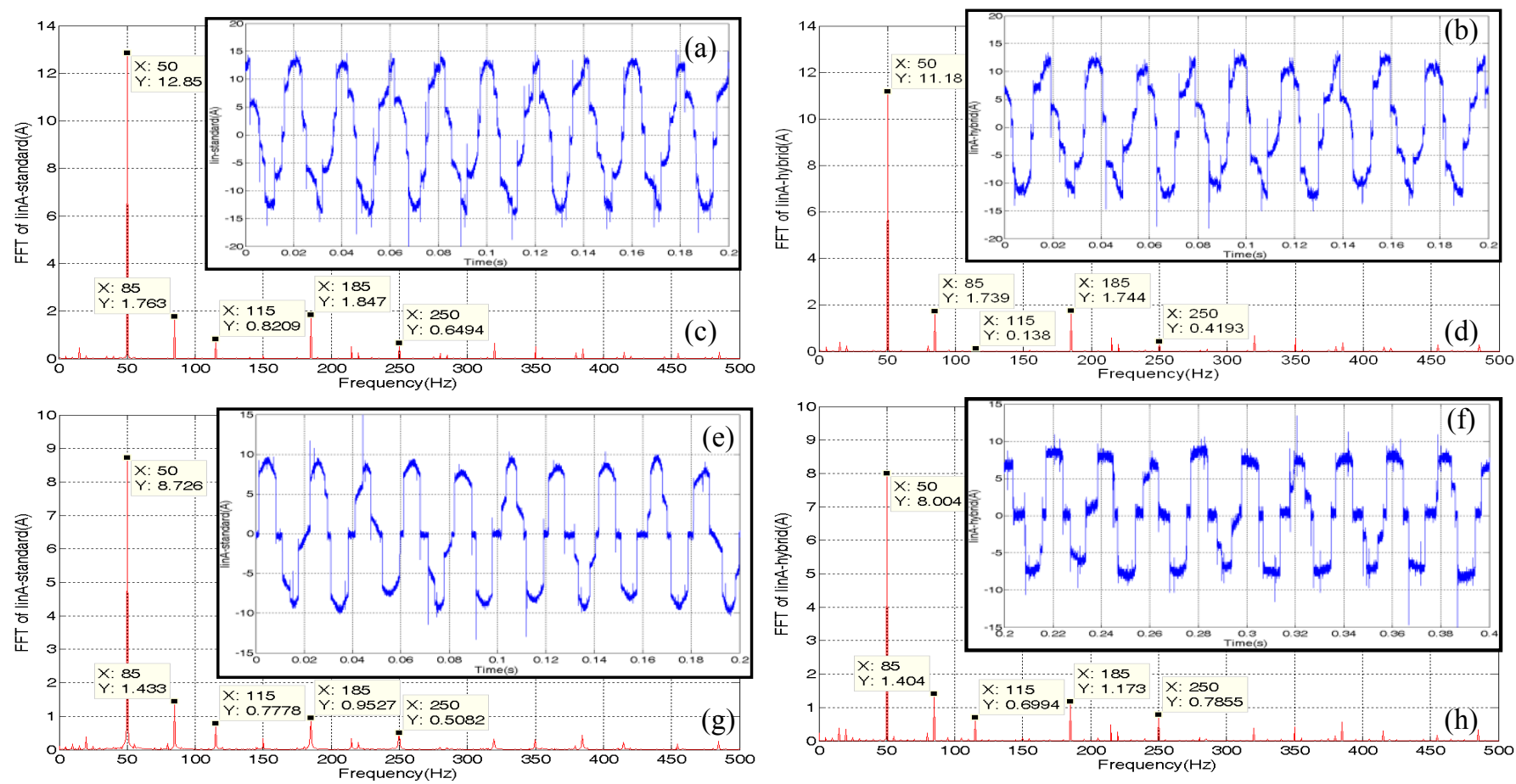

Fig. 12. Experimental results comparing the input side performance: a), b), e), f) the input current and c), d), g), h) its spectrum of the standard (left side) vs. the hybrid (right side) cycloconverters operating with (upper row)/without (lower row) circulating current.

The input current waveforms and their spectra for four situations mentioned above are shown in Fig. 12. Similar to the simulation results, the standard cycloconverter in circulating current mode draws the largest fundamental input current compared to the other three situations and therefore consumes the most reactive power from the supply by assuming the same amount of the output power are delivered to the load in all situations. This fact can also lead to a worse input displacement power factor (DPF) for this situation as shown in Table. 2, where an input side comparison between different topologies is presented. Moreover, the input distortion factor (DF) remains more or less the same for all the topologies due to the similarities in the harmonic profile of the input power. Therefore, the hybrid cycloconverters in circulating currentfree mode are able to obtain the best input power factor.

\section{CONCLUSIONS}

This paper evaluates two standard and two hybrid cycloconverter topologies that operate in circulating current and circulating current-free mode through both the simulation and experiment. The results show that the performance of the cycloconverter can be obviously enhanced by the hybrid cycloconverter approach compared to their standard cycloconverter counterparts. Although the circulating current can be accurately controlled (and therefore the better input power quality can be obtained) through the hybrid solution, the hybrid cycloconverter topology in circulating current-free mode is still more in favour of due to its better input power quality, less power devices in the auxiliary forced commutated inverter as well as no requirement of additional magetics for limiting the circulating current.

\section{ACKNOWLEDGMENT}

Support for this work from the EPSRC is gratefully acknowledged (Grant EP/C52652X/1).

\section{APPENDIX A.}

Circuit parameters for both simulation and experiment: $V_{\text {in-line }}=415 \mathrm{~V}_{\mathrm{RMS}}, f_{\text {in }}=50 \mathrm{~Hz}, f_{\text {out }}=5 \mathrm{~Hz}$, cycloconverter modulation depth $(r)=0.8 ; L_{\text {load }}=0.4 \mathrm{H}, R_{\text {load }}=20 \Omega ; L_{C C R}=$ $2 \times 100 \mathrm{mH}$ (coupled), $R_{C C R}=2 \times 0.8 \Omega ; \quad f_{s w-H B}=5 \mathrm{kHz}, V_{H B-D C}=$ $295 \mathrm{~V}, C_{d c-H B}=8200 \mathrm{uF}$.

\section{REFERENCES}

[1] B.R. Pelly, "Thyristor phase-controlled converters and cycloconverters", Wiley Interscience, 1971.

[2] W. McMurray, "The Theory and Design of Cycloconverters" Massachusetts Inst. of Tech. Press, Cambridge, MA, 1972.

[3] R. Hagmann, "AC-cycloconverter drives for cold and hot rolling mill applications", IEEE Proc. of IAS'91, Vol.2, pp. 1134-1140, 1991

[4] Y. Tamura, S. Tanaka, S. Tadakuma, "Control method and upper limit of output frequency in circulating-current type cycloconverter", IEEE Int. Semicond. Power Converter Conf., 1982, pp, 313-323.

[5] J. Trautner and A. Wick, "DC Link converter and cyclo-converter-fed AC motors: The concepts and properties of large variable-speed drives," Siemens Rev. (Energy\&Automation-Issue on Large Electric Motor\&VSD), vol. 1, pp. 16-31, 1988.

[6] H. Akagi, "Large static converters for industry and utility applications," Proc. IEEE, Vol. 89, No. 6, pp. 976-983, 2001.

[7] Y. Liu, G.T. Heydt, R.F. Chu, "The Power Quality Impact of Cycloconverter Control Strategies", IEEE Trans. on Power Delivery, Vol.20, No.2, pp.1711-1718, 2005.

[8] P. Syam, P.K. Nandi, A.K. Chattopadhyay, "Effect of output current ripple on the input supply current and the power quality for a cycloconverter-fed drive", Proc. IEE Part-B, EPA, Vol.151, No. 04, pp.425-433, July 2004.

[9] J.R. Rodriguez, J.Pontt, P. Newman, R. Musalem, H. Miranda, L.Moran, "Technical Evaluation and Practical Experience of High-power Grinding 
Mill Drives in Mining Applications", IEEE Trans. on Industry Applications, Vol. 41, No. 3, pp. 866-874, 2005.

[10] Bin Wu; J. Pontt, J. Rodriguez, S. Bernet, S. Kouro, "Current-Source Converter and Cycloconverter Topologies for Industrial Medium-Voltage Drives", IEEE Transactions on Industrial Electronics, Vol. 55 , No. 7, pp. 2786 - 2797, 2008.

[11] M. I. Milanes Montero, E. Romero Cadaval, F. Barrero Gonzalez, "Hybrid Multiconverter Conditioner Topology for High Power Applications", IEEE Transactions on Industrial Electronics, DOI: 10.1109/TIE.2010.2062478, in press.

[12] A. Jain, V. T. Ranganathan, "Hybrid LCI/VSI Power Circuit - A Universal High Power Converter Solution For Wound Field Synchronous Motor Drives", IEEE Transactions on Industrial Electronics, DOI: 10.1109/TIE.2010.2098361, in press.

[13] C. Klumpner, T. Xu, J. Clare, "A New Hybrid Cycloconverter with Smooth Output Voltage Generation Capability and Accurate Control of the Circulating Current", IEEE Proc. of IECON, pp. 2291-2296, 2006.

[14] T. Xu, C. Klumpner, J. Clare, "Hybrid Cycloconverters: An Exploration of Benefits", Proc. of EPE2007, paper \#479, 2007.

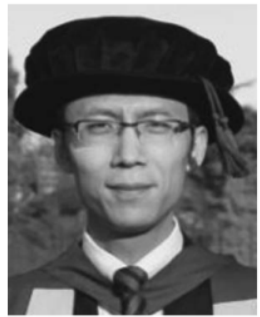

Tianning Xu received the B.Eng. degree in electrical engineering from Zhejiang University, Hangzhou, China, in 2002 and the M.Sc. degree in power electronics and drives and the Ph.D. degree in electrical and electronic engineering from The University of Nottingham, Nottingham, U.K., in 2005 and 2009, respectively.

During 2002-2004, he was an Engineer with Delta Electronics, Shanghai, China, and was involved in the design and development of standard dc/dc converters. During 2009-2011, he was with Alstom Grid, Stafford, U.K., as a Graduate Engineer. He is currently with the Power Electronics Systems R\&D Center, Alstom Grid, developing the valve used in voltage source converter.

Dr. Xu has been a member of the Institution of Engineering and Technology since 2009

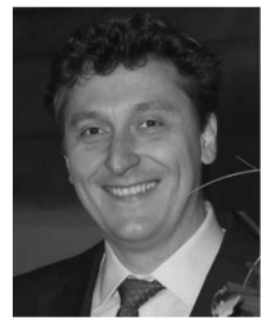

Christian Klumpner (S'00-M'02-SM'08) received the $\mathrm{Ph} . \mathrm{D}$. degree in electrical engineering from the "Politehnica" University of Timisoara, Timisoara, Romania, in 2001

From 2001 to 2003, he was a Research Assistant Professor with the Institute of Energy Technology, Aalborg University, Aalborg, Denmark. Since October 2003, he has been a Lecturer with the Department of Electrical Engineering, The University of Nottingham, Nottingham, U.K. He is a Member of the Editorial Board of the Journal of Power Electronics of the Institution of Engineering and Technology. His current research interests include power electronics for various applications, such as ac drives, connecting renewable energy sources, and energy storage devices to the ac power grid.

Dr. Klumpner was a recipient of the Isao Takahashi Power Electronics Award at the International Power Electronics Conference in Niigata, Japan, in 2005, organized by the Institute of Electrical Engineers of Japan. He is also a recipient of the 2007 IEEE Richard M. Bass Outstanding Young Power Electronics Engineer Award.

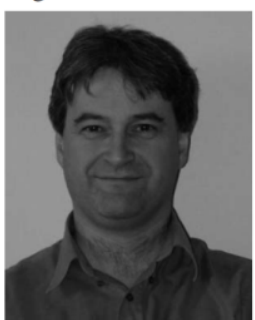

Jon Clare (M'90-SM'04) was born in Bristol, U.K. $\mathrm{He}$ received the B.Sc. and Ph.D. degrees in electrical engineering from the University of Bristol, Bristol.

Since 1990, he has been with The University of Nottingham, Nottingham, U.K., where he is currently a Professor of power electronics and the Head of the Power Electronics, Machines and Control Research Group. He is a Member of the Editorial Board of the Journal of Power Electronics of the Institution of Engineering and Technology (IET). His research interests are in power electronic system and applications, and power electronic converter topologies and their control. His work is currently directed toward applications in aerospace, energy systems, and high-power RF.

Dr. Clare is a member of IET, U.K. He is an Associate Editor for the IEEE TRANSACTIONS ON POWER Electronics. He is a former member of the Executive Council of the European Power Electronics Association and the IEEE Power Electronics Society AdCom. 